\title{
SOCIOPOÉTICA E FORMAÇÃO DO PESQUISADOR INTEGRAL
}

\author{
Jacques Gauthier* \\ * Doutor em educação. Professor de Estudos Culturais. Centro Universitário Jorge Amado (UNIJORGE). \\ E-mail: jacques.jupaty@gmail.com
}

\begin{abstract}
Resumo
Ao considerar os limites cognitivos da entrevista e as relações de poder que caracterizam as pesquisas acadêmicas foi criada a sociopoética, voltada para a constituição de grupos-pesquisadores atores e sujeitos da pesquisa, com valorização das culturas populares e de resistência, mobilização do corpo inteiro como fonte de conhecimentos, utilização de técnicas artísticas de pesquisa e dialogicidade na interação entre a academia e as comunidades anfitriões da pesquisa. $O$ autor justifica teoricamente essa abordagem e expõe os passos de realização de uma pesquisa, desde a negociação inicial até a socialização, insistindo sobre os diversos momentos, analíticos e intuitivos, sensíveis, emotivos e racionais da criação coletiva e cooperativa do conhecimento. Além de uma forte referência à filosofia de Deleuze e Guattari estão expostas técnicas e noções originais que, além dos problemas, conceitos e personagens conceituais que encontramos em obras filosóficas acadêmicas, caracterizam as pesquisas sociopoéticas.
\end{abstract}

Palavras-chave: Sociopoética; Metodologia da pesquisa; Filosofia; Interculturalidade.

\begin{abstract}
When considering the cognitive limits of the interview and the power relations that characterize the academic research was created sociopoetics toward the formation of groups-research actors and research subjects, with appreciation of popular culture and resistance, mobilizing the whole body as source of knowledge, use of artistic techniques and research in dialogical interaction between academia and the research community hosts. The author theoretically justifies this approach and exposes the steps of conducting a survey, from initial negotiation to socialization, insisting on the various moments, analytical and intuitive, sensitive, emotional and rational, to the collective and cooperative creation of knowledge. In addition to a strong reference to the philosophy of Deleuze and Guattari, techniques and original ideas are exposed that caracterize sociopoéticas research - besides the problems, concepts and conceptual personae we find in academic philosophical works.
\end{abstract}

Keywords : Poetics; Research methodology; Philosophy; Interculturalism. 


\section{A ORIGEM DA SOCIOPOÉTICA}

A Sociopoética nasceu há 20 anos a partir da necessidade de superar obstáculos que limitam consideravelmente as pesquisas qualitativas em ciências humanas e sociais, principalmente nas áreas de antropologia, saúde e educação. Pode-se dizer que todos esses obstáculos vêm da posição de poder do pesquisador e da unilateralidade da sua formação.

De fato, o questionamento radical, bastante desestabilizador, aconteceu quando, numa pesquisa de doutorado, uma das maiores e mais respeitadas autoridades indígenas perguntou, após a finalização da sua entrevista: "Respondi corretamente?" O entrevistador ficou com vergonha, pois um sábio e cientista na sua cultura estava se colocando em posição de aluno frente ao professor, enquanto a posição ética do pesquisador pretendia o oposto, ou seja, que os pesquisadores acadêmicos aprendessem com humildade dos seus informantes. Por certo, o entrevistado estava igualmente querendo verificar que suas respostas ajudavam o entrevistador na sua pesquisa, era uma forma de bondade cooperativa. Isso pode acontecer com qualquer pesquisador: ao refletir sobre o assunto, fica claro que numa entrevista, seja individual, seja coletiva, os entrevistados controlam o que dizem, ao tentarem dizer o que imaginam ser o certo (em relação ao entrevistador - como no caso citado, ou ain$\mathrm{da}$, aos interesses da sua comunidade, ou ainda, à parte consciente da sua própria mente); de qualquer maneira, eles se colocam no plano racional do autocontrole.

Vejamos o que perdemos: toda a parte não racional das informações que os entrevistados podiam dar, a qual contém, como se sabe, o que move de maneira visceral as pessoas (as emoções, o inconsciente ou subconsciente etc.); tudo o que não disseram, porque muito óbvio para eles, demais óbvio para que surja na sua mente como informação pertinente (e o óbvio, frequentemente, pertence ao que estrutura uma comunidade, portanto, é de grande relevância para um pesquisador que não compartilha os etnométodos dos seus en- trevistados, ou seja, os saberes implícitos que lhes permitem compartilhar o modo de vida da comunidade); tudo que não pode ser dito neste tipo de situação de comunicação, porque demais importante, ou muito íntimo...

$\mathrm{Na}$ sua experiência de vida, cada um de nós aprendeu que existem saberes que fundamentam seu ser, mas que ficam inacessíveis e/ou inexpressíveis pela linguagem racional, por serem rigidificados em nós nervosos, tensões musculares, alterações da voz, oriundos de traumas ou opressões internalizadas. Outros, pelo contrário estão relacionados ao prazer de viver, à boa saúde e fluem naturalmente, sem que se perceba que são saberes...

Como fazer para ter acesso a essas camadas cognitivas tão importantes, que entrevistas dificilmente poderiam alcançar? Obviamente não pretendemos chegar à transparência, tal pretensão seria apenas o efeito de uma onipotência ridícula, e duvidamos fortemente de que a transparência existe. Mas pelo menos, que um pouco do não consciente e não verbalizável entre na pesquisa é uma exigência para quem quiser ir além da superfície da vida.

A Arteterapia mostrou o caminho, juntamente com técnicas teatrais oriundas do Teatro do Oprimido de Augusto Boal.(1) Nos dois casos, a arte permite a expressão de conteúdos não conscientes (fundamentalmente, baseados em relações de desejo e de poder) e sua elaboração coletiva pelo grupo, num vai-e-vem entre o afetivo e o racional.

\section{AS ORIENTAÇÕES BÁSICAS DA SOCIOPOÉTICA}

Quando nasceu a sociopoética, conforme Gauthier, ${ }^{(2)}$ o que nos preocupava mais era, antes de tudo, a instituição de relações de poder que podemos chamar de "revolucionárias", permitindo que os grupos "objetos" das pesquisas acadêmicas se tornassem "grupos sujeitos", com referên- 
cia aos Círculos de Cultura de Paulo Freire, ${ }^{(2)}$ aos Grupos Operativos de Pichon-Rivière, ${ }^{(3)}$ à Análise Institucional e à Socianálise. (4) Também, ao tomar conhecimento de pesquisas envolvendo a arte e baseadas na sociopoética, que aconteciam de maneira, por certo, mais proveitosas e mais lúdicas, mais prazerosas, mas sem que o grupo pesquisado tome poder algum na produção do conhecimento, foi necessário colocar como primeira orientação caracterizando a sociopoética a formação do assim chamado "grupo-pesquisador", autor coletivo da pesquisa, responsável pelo seu desenvolvimento e "dono" do conhecimento produzido. $\mathrm{O}$ acadêmico, no caso, é apenas o "facilitador" da pesquisa - veremos a seguir seu papel exato (de fato, é bom ter dois facilitadores, pois não é fácil, ao mesmo tempo "facilitar" o trabalho e ficar atento a tudo o que acontece no grupo-pesquisador). Um grupo vem se formando e se torna autor coletivo de uma pesquisa sobre si próprio, sobre seu consciente e inconsciente.

Depois, e sempre em referência à preocupação política de se criar uma forma de "pesquisa do oprimido", para falar como Freire e Boal na épo$\mathrm{ca}$, colocamos como segunda orientação básica da sociopoética a valorização das culturas populares e de resistência. Dar poder ao povo na geração do saber científico significa ouvir e acolher modos não acadêmicos de se criar conhecimentos, seja através de narrativas míticas, da intuição da fala certa no momento certo, de afetos, do imaginário. O esquema de Jung colocando num eixo horizontal os sentidos e as sensações de um lado, a intuição de outro, e num eixo vertical as emoções de um lado e a razão de outro foi de grande ajuda, para que os facilitadores de pesquisa avaliassem o equilíbrio, digamos, entre os conhecimentos produzidos, em termos de razão, emoção, sensação e intuição. Gira o imaginário, assim como, a gestualidade corporal, em redor desse esquema bem prático... Em algumas pesquisas com indígenas Pataxó do Sul da Bahia, dados foram até produzidos em estado ritual de transe, colocando seres não humanos em situação de colaboradores das nossas pesquisas!
No plano teórico, esse aspecto foi recentemente radicalizado em referência, tanto a experiências de vida em comunidades indígenas e afrodescendentes como a leituras antropológicas de autores como Philippe Descola(5) ou Eduardo Viveiros de Castro. ${ }^{(6)}$ A descolonização da academia - portanto, das nossas mentes - passa pelo reconhecimento de que existem vários tipos de ciências, tanto válidos como as ciências que cresceram no chão cultural europeu (que chamo de ciências "eurodescendentes", para que possamos sair da imperialista pretensão à universalidade do saber acadêmico - que criou a palavra "afrodescendente" ou "indígena", mas que se quer acima de todos esses particularismos). A acupuntura é uma ciência, a fitoterapia indígena é uma ciência, a psicologia ioruba é uma ciência, pois, são saberes complexos e sistematizados, cuja pertinência é independente da crença das pessoas ou não nas bases culturais de onde surgiram. Não precisa ser taoísta para estar curado pela acupuntura, nem participar de uma comunidade indígena para estar curado por uma planta de poder. Esses saberes, tanto como as ciências eurodescendentes, são universais. $O$ que a contemporânea antropologia acrescenta é que não é suficiente respeitar os resultados dessas ciências (por exemplo, a cura), mas que temos de ter a humildade de acolher, também (o que não significa necessariamente compartilhar e tornar nossos) os caminhos, os métodos que permitiram a produção dos referidos conhecimentos. Por exemplo, quando um xamã nos diz que uma Planta-doutora, uma Planta-professora como a Jurema na Bahia ou a Ayahuasca na floresta amazônica, ou ainda, um sonho, the ensinou o remédio certo (e a hora certa para colhê-lo) que curou seu paciente, aceitamos essa via não racional de constituição do saber, não a julgamos nem folclórica nem inferior. Simplesmente, outra. Lévi-Strauss ${ }^{(7)}$ já teorizou muito sobre o Pensamento selvagem e suas proximidade e diferença em relação com nossas ciências acadêmicas.

Colocar em posição de dialogicidade a leitura dos dados da pesquisa - a partir dos referenciais populares de um lado, e a partir dos referenciais 
acadêmicos de outro, não é apenas uma maneira de prolongar a obra de Paulo Freire no mundo da pesquisa, mas também, de fecundar a pesquisa acadêmica: tantas dissertações e teses são pouco criadoras, por repetirem sempre as mesmas bibliografias, verificando de maneira endógena e endógama que mais uma vez tal ou qual grande autor tem razão e permite admiravelmente explicar o material encontrado na pesquisa de campo!

Agora chegam as terceira e quarta orientações que caracterizam uma pesquisa sociopoética: mobilizar todos os recursos do corpo para produzir dados: as sensações e sensibilidade, a intuição, as emoções, a razão (de tipo matemática e mítica: o logos - discurso racional lógico; o mythos - narrativas das origens ou, mais simplesmente, narrativas populares como, por exemplo, as que os filmes de Glauber Rocha encenaram; e o kairos - a percepção do momento certo para agir). E também, a gestualidade, a dança, o imaginário etc. Para mobilizar esses recursos utilizamos (e isso se constitui em quarta orientação) técnicas artísticas de produção de dados - geralmente duas numa pesquisa de mestrado e três num doutorado.

A quinta orientação consiste na responsabilidade política, social, ética, cognitiva e espiritual do grupo-pesquisador no desenvolver da pesquisa e na sua exploração. O grupo-pesquisador tem direito de pedir para certos dados não serem divulgados, já que tocaram coisas por vezes muito sensíveis; tem direito de pedir para a pesquisa servir aos interesses da comunidade, e não somente à carreira do acadêmico: por exemplo ao desdobrá-la em peça de teatro conscientizante, mostra fotográfica, vídeo, literatura de cordel etc.

Falamos sempre de "produção de dados" e não de "coleta de dados", porque a prática de pesquisa evidenciou que, da mesma maneira que não se produzem os mesmos dados numa obra plástica e numa entrevista, toda técnica induz a produção de certo tipo de dados, e impede a produção de outros. Uma das qualidades do bom facilitador de pesquisa é intuir qual a técnica mais adaptada para tal tipo de tema-gerador da pesquisa (toma- mos esse termo de Paulo Freire: pode ser qualquer noção), tal grupo-pesquisador (você não vai necessariamente utilizar a mesma técnica com criança e com pós-graduandos) e tal ambiente (certas palavras podem ser tão carregadas em tal ou qual comunidade que, apesar da pesquisa acadêmica puder ser descrita por essas palavras, é melhor substitui-las por outras, como tema-gerador apresentado ao grupo). É bom dizer, igualmente, que a segunda técnica de pesquisa depende muito dos resultados da primeira. Pode ser interessante explorar outras zonas cognitivas do grupo-pesquisador, ou quebrar dados demais unânimes, ou aplicar uma técnica que potencialmente revelará aspectos que o facilitador está intuindo (ou sabendo, pelas suas leituras) e que a primeira técnica não revelou (e eventualmente, que ela permitiu, inconscientemente, esconder).

\section{COMO ACONTECE UMA PESQUISA SOCIOPOÉTICA?}

Após a negociação da pesquisa (sobre qual tema, como, quando, onde, com quem etc.?) com a comunidade ou a instituição, um grupo-pesquisador é formado (de 6 a 16 pessoas, sendo desejável um grupo de 8 a 12 pessoas, por causa da necessidade de se ouvir cada participante e haver diferenças o suficiente: o que interesse a sociopoética é a singularidade de cada membro do grupo-pesquisador e não a busca de constantes ou tendências gerais). Certas técnicas permitem ir até umas 20 pessoas - no caso algumas entre as análises são realizadas em pequenos grupos, para tornar o processo investigativo menos cansativo.

Um relaxamento permite colocar cada copesquisador em estado próximo ao recomendado pela psicanálise - cada um estando acolhendo e expressando qualquer imagem ou ideia que surja, sem censura nem reflexão crítica. Numa visão mais "oriental", pode-se dizer que esse relaxamento permite as energias fluírem mais livremente no corpo de cada um em particular e no grupo em geral (com crianças, pode ser bom atingir o estado 
de relaxamento a partir de jogos que "esgotam" a pessoa em lugar de pedir uma difícil concentração de tipo ioga). Além disso, o relaxamento favorece a constituição do grupo-pesquisador em "continente suficientemente bom", conforme Winnicott: ${ }^{(8)}$ as pessoas se sentem à vontade para colocar coisas íntimas e vivenciar, até, conflitos, porque vivenciam o grupo como acolhedor e capaz de não emitir julgamentos. De fato, para "fazer" o grupo, antes do relaxamento é bom instituir algumas brincadeiras, como as utilizadas na formação de atores. Um diário de itinerância - tal como teorizado por René Barbier(9) - está colocado a disposição do grupo, onde poder-se-á colocar escritos, poemas, sonhos, desenhos, fotos etc. a qualquer momento. Esse diário é lido e grupalmente comentado no início de cada sessão: seus dados pertencem aos dados da pesquisa.

Em estado de relaxamento é pedido para os copesquisadores deixarem chegar uma imagem referente ao tema-gerador da pesquisa. As técnicas de inspiração artística são múltiplas e cada facilitador pode inventar técnicas que correspondem ao seu gosto e saber-fazer. Entre elas vou citar cinco, que participaram do nascimento da sociopoética:

- A técnica dos Lugares geomíticos, que sempre dá bons resultados: por exemplo, sobre o tema-gerador da saúde, relaxados, os copesquisadores deixam fluir neles uma imagem da saúde como Terra, depois, Ponte, depois, Poço, depois, Fluxos, depois, Falha, depois, Cume, Labirinto etc. Pode-se criar vários tipos de lugares geomíticos. É importante pedir detalhes sobre as imagens mentais criadas, no caso de os copesquisadores não colocarem-nas em forma de desenhos. Evitar abstração e sim, criar imagens bem concretas, o que é uma aprendizagem na nossa cultura...

- A Técnica do Teatro-imagem, diretamente inspirada em Augusto Boal. Os copesquisadores criam imagens congeladas, com um a quatro atores, apresentando um afeto potente relacionado ao tema-gerador. Cada copesquisador encena sua imagem congelada. Essa técnica é excelente para quebrar dados demais consensuais produzidos por uma primeira técnica e introduzir conflitos, dialogicidade. Ela pede para alguns exercícios de aquecimento teatral antes do relaxamento, para que se alcance um bom nível expressivo e estético. Obviamente é pedido para as imagens apresentadas não serem descrições de uma situação e sim apresentações de afetos e emoções íntimas, ligadas ao tema-gerador.

- A técnica do Conto russo, assim chamada em homenagem a Vladimir Propp, ${ }^{(10)}$ um ancestre da semiótica estruturalista. É muito pertinente em movimentos populares tentando mudar sua realidade. Imagine-se (e desenha-se em papel Canson com lápis-cera) 12 momentos: o herói da história; o objeto de desejo deste herói; um lugar onde acontece a história; um vilão que quer o mesmo objeto; uma interdição (que está presente para ser transgredida); a luta entre herói e vilão, com derrota do herói; a intervenção de um doador (humano ou não humano); um objeto dado (que pode ser material ou não); a vitória do herói; um aliado inesperado que favoreceu essa vitória; uma marca recebida; o triunfo final.

- A técnica do Jogo de Tarô, excelente em grandes grupos. Formamos 4 pequenos grupos, da Terra, do Fogo, da Água e do Ar e para cada elemento são distribuídos materiais diferentes para se realizar cartas de Tarô: papel tipo Canson, panos para limpeza das mãos, cola, água e tinta para todos, mais argila para os integrantes do grupo da Terra (que realizarão "esculturas" coladas no papel Canson), canudos e bolas de soprar para os do grupo do $\mathrm{Ar}$ (que soprarão a tinta a partir dos canudos e bolas), fósforo e lápis-cera para os do Fogo (que deixarão derreter os lápis-cera sobre as folhas), o povo da Água pintando com os dedos. Em cada carta assim produzida deve constar um desenho, tal como surgiu na imaginação, um número (depois será negociado grupalmente a organização do jogo), um símbolo e um título.

- A técnica dos Sentidos: de olhos vendados, os copesquisadores devem escolher 3 objetos reconhecidos pelo mero tato, ou 3 cheiros, ou 3 gostos etc. para qualificar o tema-gerador da pesquisa. 
É importante os facilitadores proporem objetos, cheiros, gostos, sons etc. bem diferenciados sensitivamente, entre os quais deve-se fazer sua escolha. E sobretudo, explicitar que não se trata de reconhecer e identificar (logo, de ficar no mundo utilitário da vida prática), e sim de poetizar, no sentido de se envolver na pura sensação, de se deixar penetrar e submergir...

Qualquer que seja a técnica, conforme a metodologia de Boal, cada um comenta o dado que produziu, relacionando-o (o que, às vezes, é um desafio!) com o tema-gerador da pesquisa, sem interferência, neste momento, dos demais membros do grupo-pesquisador.

Em seguida, os copesquisadores analisam "na hora" o conjunto dos dados produzidos, em conversa livre, devendo o facilitador ser o guardião do tempo e da repartição igual das falas dentro do grupo. Ele evita comentários próprios, obviamente nunca avalia, mas questiona as pessoas, o grupo, se for necessário. No meu ver, é bom exercitar os copesquisadores a melhorar sua percepção e suas sensações imediatamente antes dessa análise grupal, pois na nossa cultura, a tendência é de "não perceber as percepções", de não ficar atento às suas sensações e substituí-las por projeções sentimentais ou imaginárias. Gosto de instituir o "jogo-de-bichos", onde cada um brinca de se colocar na pele de um animal, vivenciando com intensidade a perspectiva, o mundo sensitivo e perceptivo do mesmo. Muitos risos, e muitas aprendizagens também. Imediatamente após esse jogo realizamos a análise coletiva e cooperativa pelos copesquisadores dos seus próprios dados.

Em casa, tranquilamente, o facilitador estuda o conjunto dos dados e tenta apontar as regularidades e divergências que existem no grupo-pesquisador pensado como sendo um cérebro coletivo, um filósofo com ideias em conflito, divergência ou convergência, desdobramento ou isolamento etc. Essa é a tarefa mais difícil. O objetivo é apontar o ou os problemas filosóficos que o grupo-pesquisador elaborou, sendo um problema caracterizado por uma contradição, um conflito cognitivo ou um paradoxo. Já nasce o grupo-pesquisador como filósofo mesmo!

Além disso, vão aparecer perfetos (misturas de perceptos e de afetos: os perfetos são característicos das obras de arte; podemos dizer que os artistas são potentes criadores de perfetos), confetos (misturas de conceitos e de afetos; na vida comum, pensamos por confetos, somente os filósofos profissionais tentam pensar por puros conceitos!) e intuicetos (misturas de intuição e conceitos).

É prático tecer confetos em forma de rizomas. Por exemplo, em Salvador foram criados estes confetos de saúde: - a saúde como energia-respeito-equilíbrio-paz, com afrodescendentes integrantes de um terreiro de candomblé; - a saúde como tranquilidade pessoal e social-caos institucional-responsabilidade individual e coletiva-brincadeira num grupo-pesquisador principalmente constituindo de alunos e alunas afrodescendentes evangélicos de um colégio público. Os intuicetos são delicados, mas sempre estão encontrados-criados, já que mexemos com dimensões não racionais da inteligência humana, ligadas ao cérebro direito. São intuições colocadas em forma discursiva, "conceitual". Existem técnicas que facilitam o despertar e a atuação da intuição, geralmente ignorada pela cultura acadêmica, no processo de pesquisa. O próprio facilitador deve confiar muito na sua intuição quando estuda os dados da pesquisa, "em casa". Como ele confia a priori na criatividade e inteligência coletiva do grupo-pesquisador.

Metodologicamente, realizamos uma "análise por categorização" dos dados em grandes "categorias" que se opõem, diferenciam, conforme a tradição analítica do pensamento eurodescendente. Depois, ao avesso, relacionamos o que a análise separou, no assim chamado "estudo transversal" dos dados, que dá um ponto de vista mais "oriental", ou "feminino" sobre esses dados, ao privilegiar o elo sobre a distinção: muitas vezes o estudo transversal toma forma de poemas, individuais e/ ou coletivos. Depois vem a análise filosófica: o facilitador coloca essa produção em diálogo com as teorias, academicamente valorizadas, dos pensa- 
dores da área. É um momento forte na escrita de uma tese ou dissertação. E por fim, podemos realizar, a título de experiência e brincadeira, um estudo "surreal" dos dados: para cada copesquisador será pedida uma nova produção, a partir do mais estranho e singular do que ele já produziu. Por exemplo, se isso acontecer na produção de um integrante do grupo-pesquisador, o que pode ser a saúde como sendo, ao mesmo tempo, Ponte e Poço? Ou Cume e Falha? Ou Terra e Vento?

Vem a sessão de contra-análise, em que o grupo-pesquisador avalia problemas, perfetos, confetos $e$ intuicetos - tais como foram apontados pelo facilitador. Geralmente, para facilitar o debate, os mesmos estão apresentados a partir de questionamentos. Se o grupo não concordar com as "conclusões hipotéticas" do facilitador, pode ser realmente que este não percebeu aspectos importantes do mundo da comunidade em que ocorre a pesquisa, ou que o grupo-pesquisador "resiste" ao desvelamento de parte do seu inconsciente. A contra-análise tem o mérito de tranquilizar o facilitador, já que suas "conclusões" (de fato, sua elaboração teórica a partir dos dados coletivamente criados - sem nenhuma projeção, seja pessoal, seja a partir de teorias conhecidas) estão assim "verificadas" pelo grupo-pesquisador. Esse momento sempre permite um aprofundamento da pesquisa em direções geralmente inesperadas. É um momento muito rico.

Assim vem se definindo o perfil do personagem conceitual criado pelo grupo-pesquisador na própria atividade de pesquisa. A teorização do personagem conceitual encontra-se em Deleuze e Guattari $^{(11)}$ e em Gauthier ${ }^{(2)}$ no que diz respeito às pesquisas sociopoéticas. É só pensar no "Amigo" em Platão, no "Investigador" em Hume, no "Proletário" em Marx ou no "Idiota" em Descartes. Por exemplo, personagens conceituais em relação ao tema-gerador da saúde, em dois grupos-pesquisadores indígenas Pataxó da Bahia, foram identificados, respectivamente, como Marginalizado em busca da terra, do básico, da autonomia e do mundo de fora e como Demarcador de terra-mãe com saúde e educação baseadas nos saberes dos Encantados. Esses personagens podem ser e devem ser discutidos, obviamente, com o grupo-pesquisador, a fim de detalhar suas características.

Neste momento, já estamos prontos para aplicar uma segunda técnica artística de pesquisa.

Após a segunda ou terceira técnica, é bom realizar entrevistas, individuais e/ou coletivas, baseadas na originalidade das colocações de cada um. Aí as entrevistas recebem sentido pleno, já que estão presentes os afetos íntimos de cada um, e não apenas a superfície racional das coisas.

A experiência mostrou que com oito sessões de 2 horas cada uma, mais entrevistas que podem ser programadas com mais flexibilidade, podemos realizar um bom trabalho, de tipo pesquisa de mestrado ou até, doutorado. A quantia de dados relevantes produzida é assustadora, sendo o mais difícil decidir quais os mais pertinentes!

Todos saem da pesquisa, tanto o facilitador como os copesquisadores, transformados. Não é raro vivenciarmos emoções fortíssimas, ligadas ao surgimento de fatos recalcados, de histórias de vida comoventes, e choros e risos alternam. Por isso o grupo-pesquisador deve imperativamente ser um continente bom, e o facilitador uma pessoa que traz uma energia amorosa livre de qualquer julgamento ou preconceito, no sentido do "sonhar com" cada membro do grupo-pesquisador, no sentido da capacidade de devanear segundo Winnicott. O facilitador é o mestre das técnicas de pesquisa, o guardião do tempo e do direito igual de cada um se expressar. Ele deve possuir uma grande vigilância amorosa, emanando carinho, poesia e crítica, conforme enfatiza Gauthier. ${ }^{(12)}$

\section{O LUGAR DA SOCIOPOÉTICA NA INSTITUIÇÃO ACADÊMICA: RUMO AO PESQUISADOR INTEGRAL}

O lado inovador da sociopoética permite-lhe encontrar a pesquisa-ação e as várias formas de pesquisa participante. Ela é uma intervenção na realidade so- 
cial, de tipo crítico e poético. Daqui seu nome. Mas ela não tem o propósito direto de transformar essa realidade. Primeiro, ela trabalha com as pessoas membros do grupo-pesquisador, e essas mudam no processo de pesquisa, segundo seu livre-arbítrio. Em consequência, as mesmas pessoas mudarão a realidade na qual estão inseridas. Principalmente ativa nas áreas de Enfermagem e Educação, a sociopoética pode criar configurações inéditas de pesquisa-ação, como ficar na mera perspectiva da criação de conhecimentos novos, atravessados pela percepção, pelos afetos e pela intuição.

Existem numerosas dissertações de Mestrado e teses de Doutorado, além de TTC e pós-doutorados, uma revista - Entrelugares, ${ }^{(13)}$ mantida pela Faculdade de Educação na Universidade Federal do Ceará - e múltiplos artigos e livros, referentes a pesquisas desenvolvidas na abordagem sociopoética. O reconhecimento acadêmico já é forte. Recentemente, um congresso acolheu na Escola de Enfermagem da UERJ pesquisadores de várias regiões do Brasil e dos Estados Unidos para a comemoração de 20 anos de sociopoética.

Podemos dizer que os grandes eixos da sociopoética, hoje em dia, dizem respeito à exploração dos caminhos para a autonomia de comunidades e movimentos sociais instituindo um mundo mais justo, à pesquisa inter e transcultural, ao cuidar integral e à pedagogia libertadora. A exploração das potências criativas do corpo tem um papel central nos dispositivos sociopoéticos. As alianças com movimentos populares, indígenas, afrodescendentes, comunidades urbanas e rurais, é forte. A sociopoética está criando rizomas que perpassam a academia e essas comunidades. Rizomas existenciais e rizomas de saber.

O tempo e a experiência mostrou o quanto a filosofia de Deleuze e Guattari(14) é útil para pensarmos o que acontece no grupo-pesquisador. Eventos, linhas de fuga, Corpo sem Órgão (CsO), rizomas e devires são conceitos criados pelos referidos autores que descrevem bem o que vivenciamos em pesquisas sociopoéticas. Nunca queríamos fundamentar a sociopoética numa teoria particular, ela é um método, no sentido apontado por Edgar Morin, ${ }^{(15)}$ de caminho se fazendo caminhando, e não uma teoria (ao avesso da etnometodologia, que é uma teoria do social e não um método). Mas acontece que muitos entre os sociopoetas de hoje se reconhecem em Deleuze e Guattari, além de Foucault ou Lourau e Lapassade (criadores da Análise Institucional) que sempre fertilizaram nossa reflexão. A tendência, de fato, é continuarmos o aporte de Gilles Deleuze e de Félix Guattari, notadamente, quando os grupos-pesquisadores criam novos seres filosóficos, nunca elaborados por filósofos profissionais, já que diretamente oriundos das suas experiências existenciais. Mas a sociopoética acoIhe teóricos de várias tendências, pois os conhecimentos cocriados vêm diretamente do grupo-pesquisador e apenas no momento chamado de "filosófico" os colocamos em diálogo com tal ou qual teoria de que gostamos (e, geralmente, para enriquecer essa teoria, não apenas para aplicá-la).

Para ser facilitador, é preciso, além da vigilância amorosa já citada, ousadia (gosto pelo desconhecido e arriscado) e confiança, muita confiança na inteligência coletiva, povoada de afetos e intensidades maravilhosas, do grupo-pesquisador. Um certo gosto para com a arte, as técnicas corporais, além da ciência. É neste sentido que podemos enfatizar o papel da sociopoética na formação do que chamamos de Pesquisador Integral, que sabe unificar ciência e arte, despertar as múltiplas e escondidas potências cognitivas do corpo e, assim, reconciliar saber e sabedoria, ciência e espiritualidade.

Não se trata de desprezar outras dinâmicas de pesquisa, sejam quantitativas, sejam qualitativas, mas com outro direcionamento. Trata-se de integrar o mundo da pesquisa, ao trabalharmos em níveis diferentes, cada um com suas potências e seus limites. Escolhemos a sociopoética porque pensamos e achamos ter experimentado que é a mais potente abordagem existente em termos cognitivos, mas é só uma opção, obviamente criticável. A questão é muito mais ampla que um gosto ou uma preferência. Urgente é, com efeito, a injeção da espiritualidade no conhecimento, de maneira 
metódica e complexa. Não queremos conhecer sem, ao mesmo tempo, afirmar a solidariedade, o amor e a compaixão com os outros seres vivos. Isso passa pelo enfrentamento com nossos monstros interiores, os monstros interiores do grupo-pesquisador, os monstros sociais etc. Importante neste sentido é o devir do grupo-pesquisador, principalmente quando nos sentimos atravessados por afetos que atravessam também outros copesquisadores, quando nos sentimos múltiplos, ao mesmo tempo infra e supra-individuais. Aí estão em jogo coisas fundamentais, que mexem com nosso estar-no-mundo e acontece que a pesquisa, apesar de não ser feita para isso (nunca é instituído um contrato de cura, e sim de criação de saber), tem efeitos de cura.

Neste sentido, somos integrais porque integrados. O grupo é o continente dessa integração pessoal e coletiva, integração em si mesmo e com os outros. Essa integração, sem dúvida alguma, permite lutas eficientes a favor de um mundo mais comprometido com valores essenciais de amor, justiça e solidariedade. Pelo menos, a sociopoética participa, assim, do processo de espiritualização da vida.

\section{REFERÊNCIAS}

1. Boal A. O teatro do oprimido e outras poéticas políticas. Rio de Janeiro: Civilização Brasileira; 1988.

2. Gauthier J. O oco do vento: metodologia da pesquisa sociopoética e estudos transculturais. Curitiba: CRV; $2 \mathrm{Ol} 2$.
3. Freire P. Pedagogia do oprimido. Rio de Janeiro: Paz e Terra; 1987.

4. Instituto Pichon-Rivière de São Paulo. $O$ processo educativo segundo Pichon-Rivière \& Paulo Freire. Petrópolis, RJ: Vozes; 1989.

5. Lourau R. Análise institucional e práticas de pesquisa. René Lourau na UERJ. Rio de Janeiro: Universidade do Estado do Rio de Janeiro, Departamento de Extensão; 1993.

6. Descola P. Par-delà nature et culture. Paris: Gallimard; 2005.

7. Viveiros de Castro E. A inconstância da alma selvagem. São Paulo: Cosac Naify; 2013.

8. Lévi-Strauss C. La pensée sauvage. Paris: Plon; 1962.

9. Winnicott $D W$. Jeu et réalité. $L$ 'espace potentiel. Paris: Gallimard; 1975.

10. Barbier R. A pesquisa-ação. Brasília: LiberLivro; 2006.

11. Deleuze G, Guattari F. Qu'est-ce que la philosophie? Paris: Minuit; 1991.

12. Gauthier J. Do mar ao orvalho: aprendendo a vigilância amorosa. In: Grando BS, Passos LA. O eu e o outro na escola: contribuições para incluir história e a cultura dos povos indígenas na escola. Cuiabá: EdUFMT; 2010. p. 17-19.

13. Entrelugares. Revista de sociopoética e abordagens afins. Disponível em: www. entrelugares.ufc.br

14. Deleuze G, Guattari F. Mille plateaux. Paris: Minuit; 1980.

15. Morin E. Introduction à la pensée complexe. Paris: ESF; 1990. 